\title{
HOW MUCH INCOME VARIATION "REALLY" EXISTS WITHIN A STATE?
}

\author{
Michael L. Walden*
}

\begin{abstract}
A procedure for estimating price indices in localities within one state, North Carolina, is presented and implemented. The paper makes a number of improvements over previous work, including estimating the association between local prices and national prices, and testing the potential capitalization of local taxes and public output into local prices. Intrastate income variation is reduced when the price index estimates are applied to nominal per capita incomes.
\end{abstract}

\section{INTRODUCTION}

It is now well-established that prices vary between states. Published research has found as much as a 35 percent difference between price indices for states (McMahon, 1991). However, these differences often go unrecognized in comparing the economic status of states, such as comparing the per capita incomes or average wage rates of states.

For the same reasons that prices vary between states, they should also vary between locations, such as counties, within a state. If, indeed, there are significant differences in prices within a state and they also go unrecognized, then there are a number of implications. One of the most important has to do with intra-state income variation. If prices are positively correlated with nominal income, then it means income disparities between counties within a state, and particularly disparities between urban and rural counties, aren't as great as unadjusted income numbers indicate. That is, the "rich" counties aren't as rich as they appear, and the "poor" counties aren't as poor as they appear.

Given this background, there are two purposes of this paper. First, the paper will develop a methodology for estimating price indices in local areas (counties) within a state. It is assumed that this methodology will not be direct data collection; instead, the method will be constrained to using published secondary data. Second, the local price index estimates will be used to calculate "real" per capita incomes for locations within the state, and these real incomes will be used to re-examine income disparities within the state. 


\section{PREVIOUS WORK}

There is now a large body of evidence which suggests substantial variation in prices between localities in the nation. First is evidence from direct surveys of prices in different locations in the country. One part of this evidence comes from the, now discontinued, surveys of family budgets conducted by the Bureau of Labor Statistics (U. S. Bureau of Labor Statistics, 1982). The final report of these budgets for autumn 1981 showed a 12 percent difference in budgets between metropolitan and nonmetropolitan areas of the country for a four person family with an intermediate standard of living. The largest difference existed for rent (27 percent), and the smallest difference was found for clothing, transportation, and food at home (each with a 2 percent difference between metropolitan and nonmetropolitan areas). Furthermore, similar differences were found between metropolitan and nonmetropolitan areas in regions of the country.

Other direct evidence of locational price differences comes from the American Chamber of Commerce Researchers Association (ACCRA). Each quarter ACCRA collects price data for 61 products and services in 289 locations across the country. ACCRA forms a price index by taking a weighted average of these products and services. ${ }^{1}$ For example, the first quarter, 1995 report showed a 166 percent difference between the highest cost of living location (Manhattan, New York City) and the lowest cost of living location (Kennett, Missouri). Again, the greatest difference existed for housing, at 526 percent (American Chamber of Commerce Researchers Association, 1995).

The last set of direct evidence comes from housing costs collected by the U.S. Department of Housing and Urban Development (HUD). HUD collects rent data as part of its housing subsidy programs. The rents are for units of a certain size and certain quality. Within North Carolina, for example, the 1993 data showed a 92 percent difference between the highest rent (\$545/month) and lowest rent (\$284/month) for a two bedroom apartment (U. S. Government Printing Office, 1993).

Other evidence comes from studies which estimate differences in price indices between locations. Most of these studies have focused on price differences between states or metropolitan areas (Cebula 1980; Cebula and Smith 1981; Cobas 1978; Grady 1981; Haworth and Rasmussen 1973; Hogan 1984; Izraeli 1977; Langston, Rasmussen, and Simmons 1985; Roback 1988). They also use a common methodology of specifying a reduced form equation determining the local price index, estimating the equation using available locational price data, and using the results of the estimation to calculate price indices for the states. These studies have found a maximum difference in the 
price indices among the continental states (i.e., excluding Alaska and Hawaii) of 40 percent (McMahon 1991; Nelson 1991).

Only a few studies have focused on intrastate price differences and estimation procedures. McMahon and Chang (1991) regressed ACCRA price indices for 24 metropolitan areas and 4 regional nonmetropolitan areas on per capita personal income, the value of housing, and the percentage change in population. Parameter estimates from the regression were then applied to Illinois county data for the independent variables to derive county price indices. A 60 percent difference was found between the counties with the highest and lowest price index in Illinois. Urban counties in the Chicago metropolitan area were found to have the highest price index.

Kurre (1992) estimated price indices in Pennsylvania. He also used the ACCRA data as the basis of his analysis. Unfortunately, the ACCRA data is not available for all locations (such as counties) in a state. Kurre's research process was similar to that of McMahon and Chang. His dependent variable was the ACCRA price index for all of the ACCRA communities surveyed. His explanatory variables included the community population density, total income, growth rate of total income, the local electric rate, the local cost of government services, and a regional dummy variable. Parameter estimates from this regression were then applied to data for the explanatory variables for Pennsylvania counties to form price indices. Results showed a 38 percent difference between the counties with the highest and lowest price index. Urban counties, on average, had a price index seven percent higher than rural counties.

\section{APPROACH AND DATA}

Our approach is similar to that of McMahon/Chang and Kurre. The ACCRA data will be used as the dependent variable in an equation which "explains" differences in price indices among localities. Parameter estimates from the regression equation will be applied to values of the explanatory variables for localities to form local price indices.

We have, however, made some important changes to the approach of McMahon/Chang and Kurre. First, our focus is on intrastate price differences in North Carolina, so our goal is to produce price indices for North Carolina counties. However, unlike McMahon/Chang and Kurre, we don't use ACCRA data for a single time period and from locations over the entire country to do this. Instead, we have collected ACCRA data for several time periods (specifically first quarter, 1991 through first quarter, 1994) for the ACCRA locations in North Carolina. This data set has two advantages. First, since it is confined to North 
Carolina, our regression equation will not need to include factors which account for differences between states and regions in prices. Second, since the data set is over time, it will allow us to test the relationship between national price trends and local price trends. McMahon/Chang and Kurre weren't able to do this.

A second change we made was to use the actual ACCRA price data rather than the ACCRA price indices. One reason was necessity. The ACCRA indices are not dynamic; that is, they are reconstructed each quarter. ACCRA indices for a community can be compared only to other community ACCRA indices for the same date. ACCRA price indices cannot be compared over time, either for the same community or for different communities. We constructed our own price indices from the ACCRA price data. The construction of these indices is described later. A second reason for using the raw ACCRA price data is that this allowed us to test hypotheses for individual products and services.

There are two steps to our analysis. First, we form a weighted price index from 57 ACCRA products and services and regress it on a national index and structural characteristics of the community. ${ }^{2}$ Second, the results from the regression are used to construct the price indices in North Carolina counties. The analysis uses the data set of 57 product and service prices for 20 North Carolina communities over each of the 13 quarters from first quarter, 1991 through first quarter, 1994. ${ }^{3}$

The regression equation is a reduced form. ${ }^{4}$ The regression uses the following model:

(1) $\quad \mathrm{PI}_{\mathrm{jk}}$

$=\mathbf{f}\left(\mathrm{NPI}_{\mathrm{j}}\right.$, POP $_{\mathrm{k}}, \mathrm{LAND}_{\mathrm{k}}$, POPGRW $_{\mathrm{k}}$, PROF $_{\mathrm{k}}$, PROFGRW $_{k}$, SAT $_{k}$, TAXRT $_{k}$ ),

where:

\begin{tabular}{|c|c|c|}
\hline $\mathrm{PI}_{\mathrm{jk}}$ & $=$ & $\begin{array}{l}\text { price index in time period } \mathrm{j} \text { in community } \mathrm{k} \text {; } \\
\text { national price index in time period } \mathrm{i} \text { : }\end{array}$ \\
\hline POPk $_{\mathbf{k}}$ & $=$ & $\begin{array}{l}\text { population in thousands of community } \mathbf{k} \\
\text { in July 1993; }\end{array}$ \\
\hline LAND $_{k}$ & & $\begin{array}{l}\text { land area in thousands of square miles } \\
\text { of community k in July 1993; }\end{array}$ \\
\hline POPGRWk & $=$ & $\begin{array}{l}\text { population growth rate of community } k \\
\text { from } 1990 \text { to } 1993 \text {, but not including annexations }\end{array}$ \\
\hline $\mathrm{PROF}_{\mathrm{k}}$ & $=$ & $\begin{array}{l}\text { thousands of persons in community } k \text { in } \\
\text { a professional or managerial occupation in } 1990 \text {; }\end{array}$ \\
\hline PROFGRW $_{k}$ & $=$ & $\begin{array}{l}\text { the ratio of the percentage of persons } \\
\text { in community k having a professional or } \\
\text { managerial occupation in } 1990 \text { to the same } \\
\text { percentage in 1980; }\end{array}$ \\
\hline
\end{tabular}




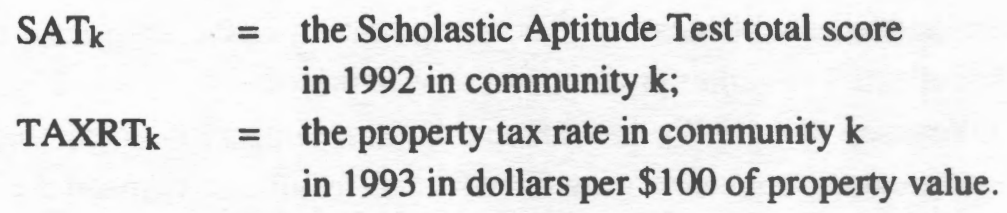

The local price index, $\mathrm{PI}_{\mathbf{j k}}$, was constructed in the following way. First, the ACCRA prices for each product or service were converted to indices (based on 100 for first quarter, 1991). In doing this, the housing cost was taken as the monthly amortized mortgage payment based on the house price, mortgage rate, a 30 year term, and a 25 percent down payment. Second, the weights used by ACCRA in forming their index were applied to the products and services. ${ }^{5}$ The ACCRA weights, rather than the CPI weights, were used because the ACCRA products and services don't correspond exactly to the products and services which compose the CPI market basket. ${ }^{6}$ Third, the local price index was calculated as the product of the weights and the indices for the products and services.

The same procedure was used in developing the national price index, $\mathrm{NPI}_{\mathbf{j}}$. The CPI indices for each product or service were recalculated to make the base period (index value of 100) be the first quarter of 1991. The weights were the ACCRA weights. The national price index was constructed as the product of the weights and the indices for the products and services. It is expected that local price trends will follow national price trends. Therefore, the sign of the regression coefficient on $\mathrm{NPI}_{j}$ is expected to be positive.

Other studies, such as Kurre's, include population and population density (population per land area) as regressors in their form of equation 1. However, doing this includes population twice, once standing alone, and second in the numerator of density. Such a form of equation 1 may introduce collinearity problems. In this study we simply include population $\left(\mathrm{POP}_{\mathbf{k}}\right)$ and land area $\left(\mathrm{LAND}_{\mathrm{k}}\right)$ as individual regressors.

The expected impact of population on local prices is ambigous. On the one hand, holding land area constant, higher population should lead to greater demand for fixed inputs, such as land, which in turn will be passed through in the form of higher prices. But conversely, greater local population can mean more competition in the local production of products and services and to greater economies of scale in production, both of which would lead to lower local prices. Thus, the impact of population on local prices is, a priori, indeterminant.

Similarly, there are likely counteracting impacts of $\mathrm{LAND}_{\mathbf{k}}$ on prices. Holding population constant, greater land area will mean less demand per unit of fixed inputs, such as land, and this will lead to lower local prices. Conversely, 
greater land area will mean higher transportation costs, and these higher costs will be reflected in higher product and service prices.

Likewise, POPGRW $\mathrm{W}_{\mathbf{k}}$ has an ambiguous impact on local prices. Ceteris paribus, greater population growth will lead to greater demand for fixed local inputs and to higher local prices. But also, greater population growth can mean greater land competition and economies of scale in production. Note that our measure of population growth excludes growth coming from annexation.

The McMahon/Chang and Kurre studies included per capita income as a regressor in their versions of equation 1. Their reasoning is that higher levels of per capita income should increase the demand for local products and services (i.e., shift the demand curve to the right) and result in higher local prices. However, the variable that should be used is "real" per capita income, that is, per capita income adjusted for a local price index. Obviously, we don't have the local price index. Thus, it is somewhat circular reasoning to include unadjusted per capita income in an equation determining the local price index, and then to use the results of that equation to construct a local price index and to further apply that index to adjusting per capita income.

Instead, we include two variables, PROF $_{k}$ and PROFGRW $k$, to account for the likely higher demand for products and services of higher income persons. Professional and managerial occupations have the highest average incomes. Controlling for the total local population, a greater number of persons having a professional or managerial occupation should mean higher average local real income and a rightward shift in the demand curve. ${ }^{7}$ Similarly, higher values for PROFGRW $_{k}$, which measures the increase in the percentage of persons having professional or managerial occupations between 1980 and 1990, should be related to greater increases in local real income. On the basis of these associations, the sign of the regression coefficients for both $\mathrm{PROF}_{k}$ and PROFGRW $_{k}$ should be positive.

The last two variables, $\mathrm{SAT}_{k}$ and $\mathrm{TAXRT}_{k}$, are included to account for possible capitalization effects on local prices of differences in local public output and local tax rates. The well known Tiebout hypothesis suggests that households "vote with their feet" by leaving localities with inefficient public sectors and entering localities with efficient public sectors. This means that localities with high tax rates and not comparably higher public output will have this inefficiency capitalized into lower land values, and consequently lower local prices. Conversely, localities with high public output and not comparably higher tax rates will have this efficiency capitalized into higher land values, and consequently higher local prices.

We use as a representative measure of local public output the Scholastic Aptitude Test total score in 1992 (the last year available) in the local public 
school system. Clearly this score is not a result of only public school inputs. Considerable research has shown that characteristics of the students, such as parental education, are major contributors to school outcomes (Hanushek, 1986). We control for this effect by including PROF $F_{k}$ in equation 1 , since professional and managerial occupations require the greatest amounts of education. Therefore, we expect the sign on the regression coefficient of $\mathrm{SAT}_{k}$ to be positive.

We expect the sign on the regression coefficient of the local tax rate, $\mathrm{TAXRT}_{k}$, to be negative. Controlling for the level of local public output, higher local tax rates will be capitalized into lower land values and lower local prices. ${ }^{8}$

In the second step, the results of equation 1 were used to construct price indices for each of North Carolina's counties. The parameter estimates from equation 1 were applied to values of the regressors for each of North Carolina's counties to calculate estimates of the price indices.

\section{RESULTS}

Means and standard deviations for the variables in the regression analysis are given in Table 1. The results for the price index regression are in Table 2. Almost half of the variation in the dependent variable is explained by the right-hand side variables.

All of the parameter estimates are statistically significant except for LAND. The positive coefficient on NPI of near 0.47 indicates that approximately

TABLE 1

Means and Standard Deviations of Variables in Regression Analysis

\begin{tabular}{lrc} 
Variable & Mean & Standard Deviation \\
\hline NPI (index) & 106.82 & 4.05 \\
POP (thousands of persons) & 69.49 & 88.05 \\
POPGRW (\%) & 3.60 & 2.90 \\
LAND (thousands of square miles) & 0.49 & 0.19 \\
PROF (thousands of persons) & 7.21 & 13.17 \\
PROFGRW (ratio of percentages) & 1.14 & 0.12 \\
TAXRT (dollars) & 0.87 & 0.21 \\
SAT (score) & 830.02 & 48.36 \\
\hline
\end{tabular}


TABLE 2

Price Index Regression Results

Dependent Variable: COL

Regressors:

Parameter Estimate

t-value

$\begin{array}{lrl}\text { Intercept } & 44.6289 & 1.702^{*} \\ \text { NPI } & 0.4671 & 1.806^{*} \\ \text { POP }(1,000 \text { 's }) & 0.0186 & 3.991^{* * *} \\ \text { POPGRW } & 0.7093 & 3.892^{* * *} \\ \text { LAND }\left(1,000^{\prime} \text { 's }\right. & 0.2390 & 0.078 \\ \text { PROF }(1,000 \text { 's } & -0.0355 & -2.042^{* *} \\ \text { PROFGRW } & -5.8460 & -1.624^{*} \\ \text { TAXRT } & -9.1844 & -6.855^{* * *} \\ \text { SAT } & .0330 & 3.875^{* * *}\end{array}$

$\bar{R}^{2}=0.4984$

$\mathrm{F}$ - value $=21.869^{* * *}$

$\mathrm{N}=169$

* significant at 0.10 level

** significant at 0.05 level

*** significant at 0.01 level

one-half of every one point change in the national price index is passed on to the local index. ${ }^{9}$

The parameter estimates on POP and POPGRW are both positive. The results indicate that the local price index is almost 0.02 points higher for every additional population count of 1000 persons, and the index is 0.71 points higher for every additional one percentage point in the population growth rate.

The parameter estimates for the two demographic variables are negative, contrary to expectations. An explanation may be the following. If professional households are more knowledgeable shoppers, then communities with a greater proportion of professional households, or with greater growth in their proportion, may have more competition among local businesses and hence lower prices. This "competitive effect" may outweigh the effect of greater demand for goods and services caused by professional households' higher incomes. The two public sector variables have the expected signs. Higher local property tax rates are capitalized into a lower local price index, and higher local SAT scores are capitalized into a higher local price index. 
FIGURE 1

Estimated Price Indices for North Carolina Counties

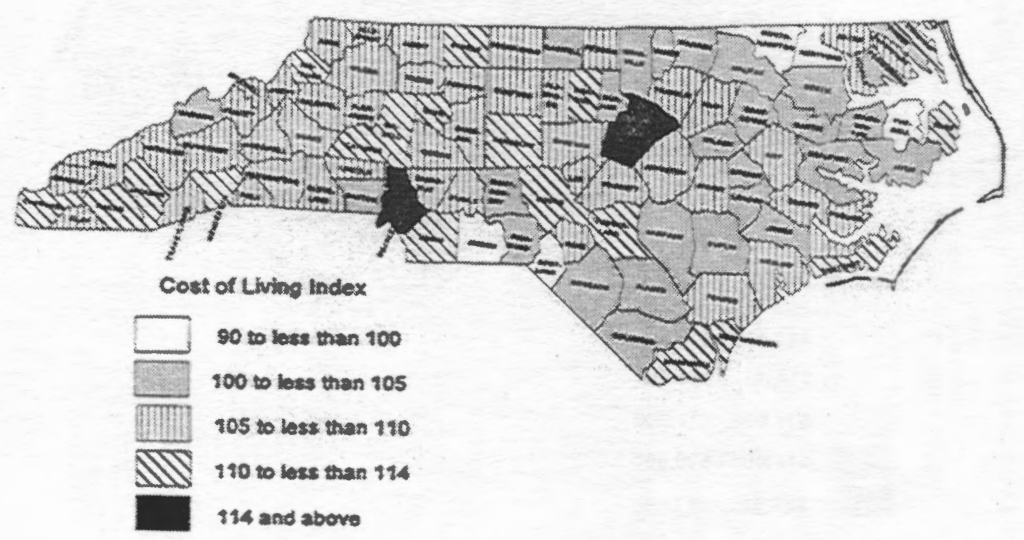

The parameter estimates in Table 2 were applied to values for the regressors for each of North Carolina's 100 counties to produce county price index estimates. The value of NPI used was for the third quarter of 1993 (98.0606), so the price indices estimates are for that date.

The county price indices are shown in Figure 1. The range in the index is from a low of 94.585 for Northampton County to 118.176 for Wake County, for a range of 25 percent. This is a smaller range than found in the studies of Illinois and Pennsylvania, but North Carolina does not have large, high-cost metropolitan areas comparable to Chicago and Philadelphia.

The geographic distribution of the estimated county price indices makes sense. The two highest cost counties are the state's two leading urban counties, Wake (site of Raleigh) and Mecklenburg (site of Charlotte). Other high cost counties are in the industrial central Piedmont area, fast growing coastal counties, and rapid growing retirement counties in the western part of the state. In contrast, lower cost counties include rural and slower growing regions in the northeast and southeast sections of the state. 
FIGURE 2

Nominal Per Capita Incomes in North Carolina Counties

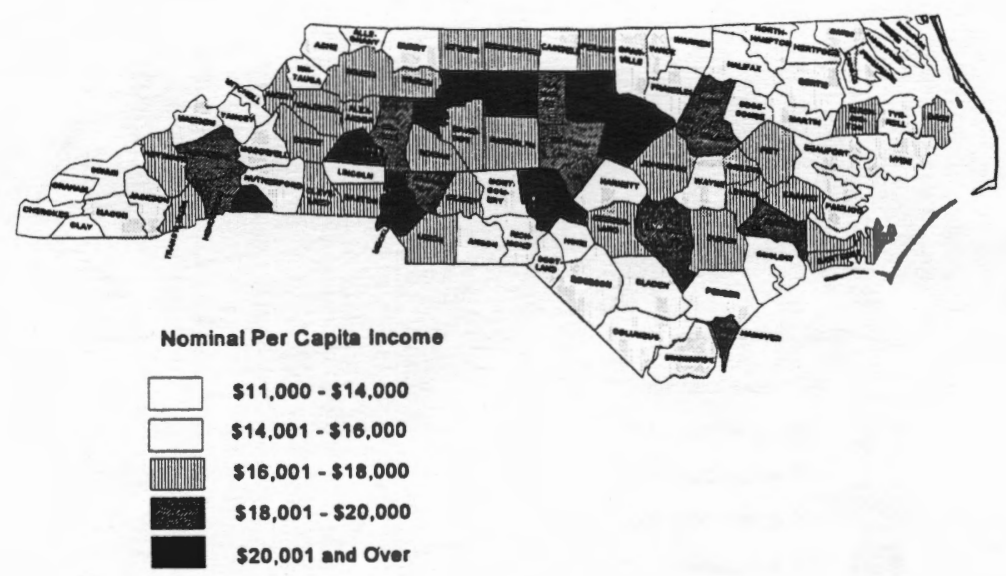

\section{APPLICATIONS}

An important use of the county price indices is adjusting nominal county incomes to form real county incomes. In this section, county per capita incomes are adjusted by the price indices, and the resulting change in income disparity between counties is examined.

First, a brief description of the income disparity among North Carolina counties using nominal data is presented. Using 1993 data, nominal per capita income is highest in Mecklenburg County (Charlotte) at $\$ 24,612$, and is lowest in Hoke County at $\$ 11,921$ (see Figure 2). This is a difference of 106 percent. The five highest nominal per capita income counties (Mecklenburg, Wake, Forsyth, Guilford, and Polk) are either urban, Piedmont counties or retirement counties (Polk). The five lowest per capita income counties (Hoke, Graham, Warren, Swain, and Hertford) are all rural counties, although Warren is in the Raleigh-Durham metropolitan area.

Figure 3 shows the real per capita incomes of the counties after adjusting by the county price indices. The price index for the highest cost county (Wake) is used as the base, so the incomes are in terms of "Wake County purchasing power dollars". The highest real income county (Forsyth) has an income of $\$ 25,936$, and the lowest real income county (Hoke) has an income of $\$ 13,250$, for a difference of 96 percent. Several counties (Anson, Hertford, Northampton, 


\section{FIGURE 3}

Real Per Capita Incomes in North Carolina Counties

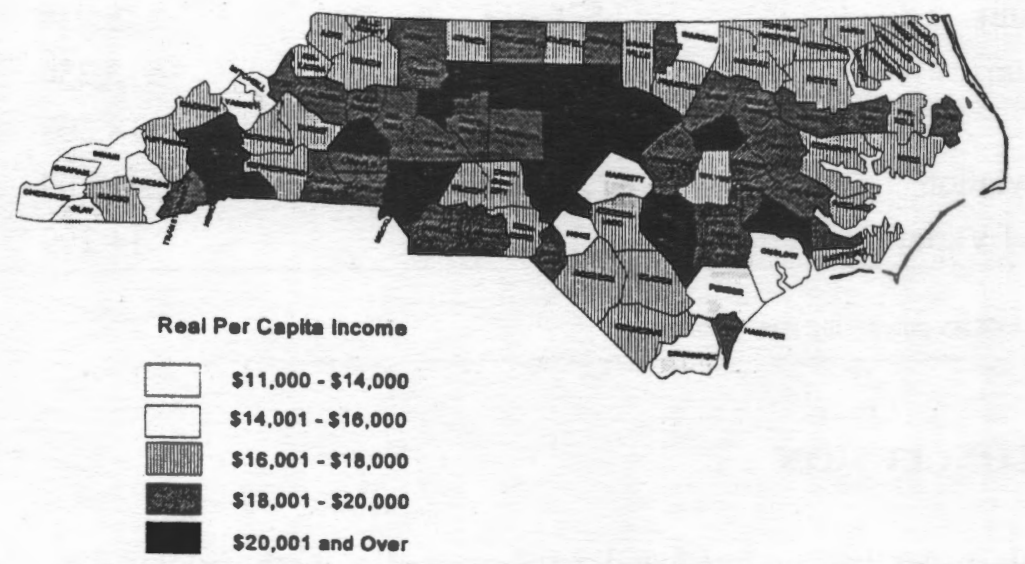

Scotland and Tyrrell) had gains of real income over nominal income of 15 percent or more. As expected, there are now more counties in the two highest income categories. However, the geographic pattern of real per capita incomes is similar to that for nominal incomes. The highest income counties are still in the central Piedmont region, plus some retirement counties in the western part of the state. One difference is the addition of some high income counties in the eastern part of the state when real incomes are used.

Table 3 compares the descriptive statistics for the nominal and real per capita county incomes. We would expect that the use of real incomes would reduce the variation in income measures between the counties. Since the highest cost of living county is used as the base in the real income calculations, it is likely that the real income maximum, minimum, and mean are higher in the real income calculations than for the nominal incomes. Table 2 shows this. The standard deviations are essentially the same for real income and nominal income. However, the measure of relative variation, the coefficient of variation, does show a decline in moving from nominal to real income.

There are many other applications of county price indices. Counties with low price indices can use this information in recruiting new businesses. States can use the county price indices to adjust transfer payments, such as AFDC, and public school aid to equalize their real values by county. 
TABLE 3

Comparison of Nominal and Real County Per Capita Incomes

Nominal Income

Real Income ${ }^{\mathrm{a}}$

\begin{tabular}{lrr} 
Maximum & $\$ 24,612$ & $\$ 25,936$ \\
Minimum & $\$ 11,921$ & $\$ 13,250$ \\
Mean & $\$ 16,564$ & $\$ 18,303$ \\
Std. Deviation & $\$ 2,617.65$ & $\$ 2,617.09$ \\
Coeff. of Variation & 15.803 & 14.299 \\
\hline
\end{tabular}

ain "Wake County purchasing power dollars"

\section{CONCLUSION}

This paper has outlined and implemented a methodology for calculating local price indices. The methodology makes use of the quarterly available ACCRA data, and can be implemented for many states or regions. Although the model explained almost 50 percent of the variation in a local price index, there is certainly room for additional future work to improve this performance.

Using the estimated county price indices to convert nominal county per capita income to real per capita income reduces intra-state income variation, but doesn't eliminate it. The general pattern of intra-state variation in per capita income is maintained when real incomes are used.

\section{ENDNOTES}

1. Even though ACCRA calls their index a cost of living index, it is referred to here as a price index because it calculates the cost of buying the same products and services in different locations. A cost of living index would calculate the cost of maintaining the same utility in different locations.

2. The ACCRA products and services represent the major categories of consumer expenditures, including food products (meats, dairy, vegetables, bread), personal items, housing, utilities, transportation services, health care services (doctor and dentist visits), clothing, restaurant food, and entertainment items. We did not include four ACCRA items, apartment rent, commuter fare, monthly electricity cost, and other monthly home energy costs. The first two items weren't included because they weren't available for all North Carolina 
cities surveyed by ACCRA. The second two items weren't included because they are subcomponents of an included item, total monthly home energy cost.

3. The North Carolina communities are Asheville, Burlington, Charlotte, Gastonia, Fayetteville, Greensboro, Winston-Salem, Chapel Hill, Durham, Raleigh, Dare County, Eden, Greenville, Hickory, Marion, Rocky Mount, New Bern, Goldsboro, Rockingham, and Statesville. They are from locations all across the state. However, since the price data weren't available for each of these communities each quarter, the data set is not a true panel.

4. For a relevant structural model, see McMahon (1991).

5. The same weights are used for all counties because the index being formed is a price index which calculates the cost of buying the same products and services in different locations. This is in contrast to a cost-of-living index which would use different county weights to calculate the cost of maintaining the same utility level in different locations.

6. The ACCRA weights are based on the buying patterns in the Consumer Expenditure Survey of households with middle management occupations (American Chamber of Commerce Researchers Association, 1995, p. i). Thus, they may not be completely representative of all households.

7. PROF is measured as number of persons, rather than as a percent of the population, because total population (POP) is included as a right-hand-side variable.

8. In cases where there was more than one taxing district or school district in a county, TAXRT and SAT are district population-weighted averages of the multiple rates or scores in the county.

9. The NPI variable is, however, only statistically significant at the $\mathbf{0 . 1 0}$ level. The low level of statistical significance likely reflects the large amount of "noise" in the transmission of national prices to the local level.

\section{REFERENCES}

American Chamber of Commerce Researchers Association. "ACCRA Cost of Living Index, First Quarter 1995." 28 (1995).

Board of Governors of the Federal Reserve System. Federal Reserve Bulletin, Table A37. (1991-1994).

Cebula, Richard. "Determinants of Geographic Living Cost Differentials in the U. S.: An Empirical Note," Land Economics. 56 (1980). 477-481.

Cebula, Richard and Lisa Smith. "An Exploratory Empirical Note on Determinants of Inter-Regional Living-Cost Differentials in the U. S., 1970 and 1975." Regional Science and Urban Economics. 11 (1981). 81-86. 
Cobas, J. A. "A Method to Estimate the Bureau of Labor Statistics Family Budgets for All Metropolitan Statistical Areas." Social Science Quantity. 59 (1978). 546-552.

Grady, S. T. "Estimation and Evaluation of State Price Indexes for the Period 1967-1978: An Empirical Note." Review of Regional Studies. 11 (1981). 51-62.

Hanushek, Eric. "The Economics of Schooling: Production and Efficiency in the Public Schools." The Journal of Economic Literature. 24(1986). 1141-1177.

Haworth, C. T., and D. W. Rasmussen. "Determinants of Metropolitan Cost of Living Variations.” Southern Economic Journal. 40 (1973). 182-192.

Hogan, T. D. "Geographical Living-Cost Differentials in the U.S.: A Disaggregated View." Land Economics. 60(1982). 115-119.

Izraeli, O. "Differentials in Nominal Wages and Prices Between Cities." Urban Studies. 14 (1977). 275-290.

Kurre, James. The Cost of Living in Rural Pennsylvania. Erie, Pennsylvania: The Center for Rural Pennsylvania, 1992.

Langston, D., D. W. Rasmussen, and J. C. Simmons. "A Note on Geographic Living Cost Differentials." Land Economics. 61 (1985). 314-318.

McMahon, Walter W. "Geographical Cost of Living Differences: An Update." Journal of the American Real Estate and Urban Economics Association. 19 (1991). 426-450.

McMahon, Walter W. and Shao-Chung Chang. Geographical Cost of Living Differences: Interstate and Intrastate, Update 1991. Normal, Illinois: Center for the Study of Education Finance, 1991.

Nelson, F. Howard. “An Interstate Cost-of-Living Index," Educational Evolution and Policy Analysis. 13 (1991). 103-111.

Roback, J. "Wages, Rates, and Amenities: Differences Among Workers and Regions," Economic Inquiry. 26 (1988). 23-42.

U.S. Bureau of the Census. Price Index of New One-Family Houses Sold. Series C27, Washington, D.C., 1991-1994.

U.S. Bureau of Labor Statistics. "Family Budgets." Monthly Labor Review. 107 (1982). 44-46.

U.S. Government Printing Office. Federal Register. 58, 189 (1993). October 1. 51449-51450. 